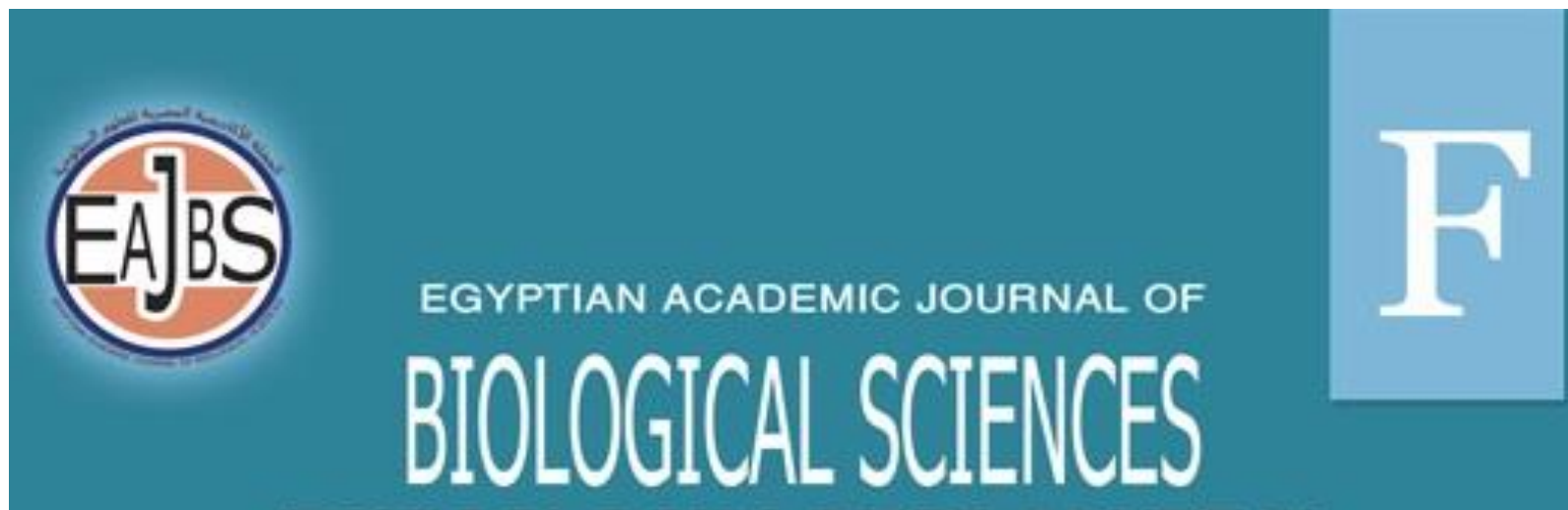

TOXICOLOGY \& PEST CONTROL

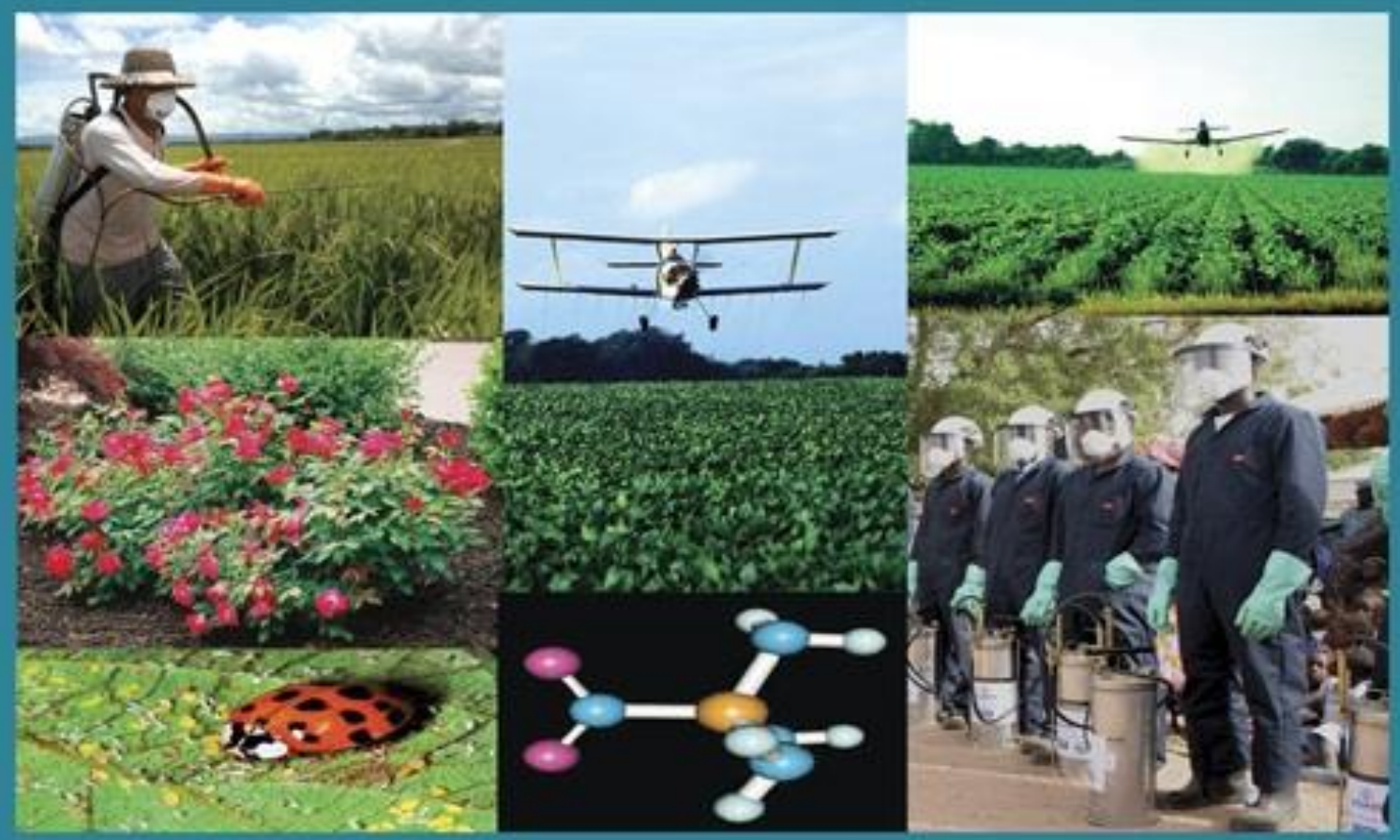

ISSN

2090-0791

WWW.EAJBS.EG.NET

Vol. 13 No. 1 (2021)

$\underline{\text { www.eajbs.eg.net }}$

Citation :Egypt. Acad. J. Biolog. Sci. (F.Toxicology\& Pest control) Vol.13(1)pp143-148(2021)

DOI: 10.21608/EAJBSF.2021.152629 
Egypt. Acad. J. Biolog. Sci., 13(1):143- 148(2021)

Egyptian Academic Journal of Biological Sciences

F. Toxicology \& Pest Control

ISSN: 2090 - 0791

http://eajbsf.journals.ekb.eg/

\title{
Toxicity and Residual Efficacy of Lambada -Cyhalothrin Insecticide Applied on Cement and Polyethylene Surfaces against Rhyzopertha dominica and Callosobruchus maculates.
}

\author{
Doaa Mahmoud Gharib², Naima Abd El Raouf Abd El razik², Mohamed Adel \\ Hussein Tawfik $^{1}$,Sanaa Mahmoud Mahgoub ${ }^{2}$ and Shams Fawki ${ }^{1}$ \\ 1-Entomology Department, Faculty of Science, Ain Shams University. \\ 2-Stored Grain Pests Research Department, Plant Protection Research Institute, \\ Agricultural Research Center. \\ *E-Mail: doaa.mahmoud786@yahoo.com
}

\section{ARTICLEINFO}

Article History

Received: $16 / 12 / 2020$

Accepted: 17/2/2021

Keywords:
Rhyzopertha
dominica,
Callosobruchus
maculates,
Insecticides,
Lambda-
cyhalotrhrin,
Different surfaces,
Initial and residual
efficacy.

Keywords:

Rhyzopertha

dominica

Callosobruchus

maculates,

Insecticides,

cyhalotrhrin, efficacy.

\section{ABSTRACT}

Laboratory studies were undertaken to assess the initial and persistence of lambada -Cyhalothrin insecticide on some porous and some non-porous surfaces. Formulation of insecticide was applied to polyethelyne and cement surfaces which are materials commonly used for grain storage facilities (packages) and in the construction of silos or storage. Lambada -Cyhalothrin insecticide was applied at concentrations $15.7,7.8,3.93,1.9,0.949$ to $0.479 \mathrm{~g} / \mathrm{m}^{2}$ to test surfaces to determine $\mathrm{Lc}{ }_{95}$ to study their persistence against Rhyzopertha dominica and Callosobruchus maculates adults. Insects were exposed on treated surfaces Initial and residual efficacy was determined after 24 hrs. of insects contact with 7, 14, $30,60,90,120,150,180$ days of exposure deposits on each surface. Results indicated that; mortality rates were positively correlated with the concentration and negatively correlated with the time of application. Results indicated that:

-Polyethylene was the most persistent surface which gave 100\% mortality up to 6 months in Callosobruchus maculates and up to 5 months in Rhyzopertha dominica at the highest concentration in both tested insects.

- In cement surface lambada cyhalothrin deteriorated very rapidly starting from the first month on both tested insects.

\section{INTRODUCTION}

The lesser grain borer, Rhyzopertha dominica and broad bean beetle, Callosobruchus maculates were economic pests of stored wheat(Triticum sativum) grains and faba bean (Viciafaba L.) seeds which found in all facilities used for storage and processing of plant products. Use of contact (residual) insecticides, most liquids and occasionally dusts, is very common in the management of food industry arthropod pests, particularly in storage where, besides regular hygiene measures, treatment of storage area and surfaces is necessary to ensure fast death of existing pests and a long -term protection (Daglish 2006). However, flooring surfaces in food storage facilities are made with 
different materials which can significantly interfere with the activity of different formulated contact insecticides (Nayak et al., 2002).

Insecticidal efficacy and persistence will vary depending on the type of surface, type of insecticide, species of insects, or duration of exposure as documented in many studies on stored product insects. (Collin et al., 2000, Jankuv et. al., 2013 and Rumbos et al., 2014).

The residual efficacy and persistence of deltamethrin insecticide against Sitophilus oryzae (L.) and Rhyzopertha dominica (F.) adults on steel, ceramic tile, plywood, and cement (wall or floor surfaces) and plastic, Damour, polypropylene and jute (fabric surfaces) after their application (Nasr and Mahgoub 2017).

Wp-wettable powder and cs-capsule suspension, compound Lambada-cyhalothrin is known as one of the most widely used insecticides for control of cockroaches, flies, important vectors and pests in public health, food industry (Who 2006, Tomlin 2006 and Anonymus2009). There is very little data on the efficacy of contact insecticides applied to different surfaces against Rhyzopertha dominica and Callosobruchus maculates and on the effects of Lambada-cyhalothrin on storage pests, for this reason, the aim of the study was to investigate the initial and residual efficacy of Lambada-cyhalothrin applied to cement and polyethelyne surfaces against laboratory population of Rhyzopertha dominica and Callosobruchus maculates.

The researchers have made progress in that direction. The reason is the fact that in food products storages grain products are becoming very common, and so are the grain pests.

The effectiveness of the treatments was influenced by the type of surface, the insecticide, its concentration and the age of deposits. The treated surfaces were bioassay up to 12 months on each surface after initial treatment.

\section{MATERIALS AND METHODS}

The wheat grains and faba bean seeds used in the present work was been Egyptian wheat (Triticum sativum) variety (Sakha 93) and faba bean (Vicia faba L.) variety (Giza 2). Kept in the freezer at $-20^{\circ} \mathrm{C}$ for two weeks before use. Moisture content is stabilized at approximately $11.5 \%$. The disinfested grains and seeds were then placed in clean jars and covered tightly.

-Tested insects: The grain borer, Rhyzopertha dominica and the cowpea beetle, Callosobruchus maculates.

- Commercial formulation Lambada cyhalothrin insecticide was applied on polyethylene Individual discs were prepared by cutting a circular disc to fit petri dishes $(1.5 \mathrm{~cm}$ high $\times 9$ $\mathrm{cm}$ diameter), while, cement discs were prepared by mixing $3.2 \mathrm{~kg}$ of cement in $1600 \mathrm{ml}$ of water, which was subsequently put into individual Petri dishes fig. (1), $1 \mathrm{ml}$ of each concentration was applied on discs to obtain deposits 15.7, 7.8, 3.93, 1.9, 0.949 and 0.479 $\mathrm{g} / \mathrm{m}^{2}$. To evaluate the persistence efficiency of Lambada-cyhalothrin on different surfaces applied 2x Lc 95 (twice Lc 95) against the tested insects, 25 adults of each insect species were released on surfaces after $24 \mathrm{hrs}$. from the application ( 0 times) then introduced periodically at one-week intervals up to 12 months old deposits after initial treatments. In all cases, three replicates were made for each treatment. The percentages mortality was recorded after $24 \mathrm{hrs}$. from adults exposure and corrected with Abbott's formula (1925). 


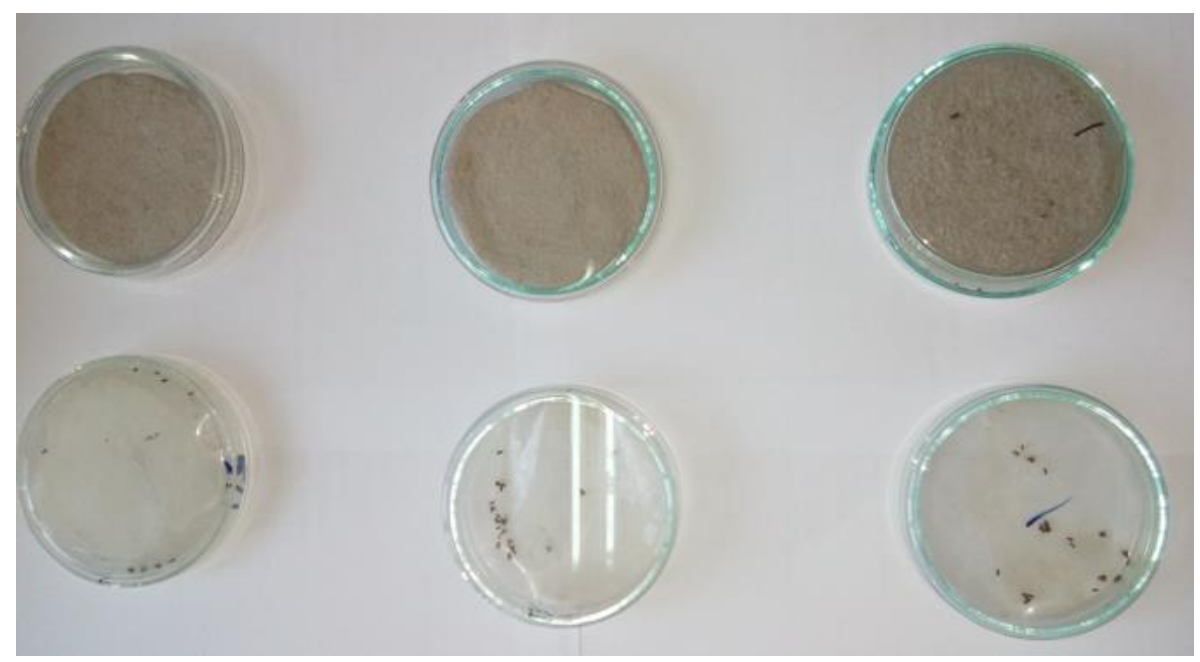

Fig. 1: Types of surface substrates

\section{RESULTS}

Results in table (1) showed that the toxicity of insecticide was different on the surface substrates. Survival of insects was lower on cement surface than polyethelene. At all tested concentrations, Rhyzopertha dominica adults were highly susceptible to Lambada-cyhalothrin insecticide than Callosobruchus maculates which showed less susceptibility at two tested surfaces.

Data in table (1) showed clearly the mortality rates of Rhyzopertha dominica and Callosobruchus maculates after treated with tested insecticide on tested surfaces. Results showed that there was a positive correction with the time of application.

Table (1) revealed that polyethylene had high mortality of $95 \%$ and $98.5 \%$ with Callosobruchus maculates and Rhyzopertha dominica respectively, meanwhile cement surface gave $80 \%$ and $96 \%$ with two tested insects Callosobruchus maculates and Rhyzopertha dominica respectively. At concentration $0.949 \mathrm{~g} / \mathrm{m}^{2}$ polyethylene surface recorded $50.5 \%$ and $38.5 \%$ mortality with Callosobruchus maculates and Rhyzopertha dominica respectively, but, in cement, surface gave $17.5 \%$ and $28.5 \%$ mortality with Callosobruchus maculates and Rhyzopertha dominica respectively.

Table1: percentage mortality of Callosobruchus maculatus and Rhyzopertha dominica adults on some non-porous surface treated with lambada-cyhalothrin insecticide at different concentrations

\begin{tabular}{|c|c|c|c|c|}
\hline \multirow{2}{*}{$\begin{array}{c}\text { Concs. } \\
\mathrm{g} / \mathrm{m}^{2}\end{array}$} & \multicolumn{4}{|c|}{ Percentage mortality\% } \\
\cline { 2 - 5 } & Callosobruchus maculates & \multicolumn{2}{|c|}{ Rhyzopertha dominica } \\
\cline { 2 - 5 } & Tested surfaces & Tested surfaces \\
\cline { 2 - 5 } & Polyethylene & Cement & Polyethylene & Cement \\
\hline 15.7 & 95 & 80 & 98.5 & 96.5 \\
\hline 7.8 & 81.5 & 50.5 & 86.5 & 68.5 \\
\hline 3.93 & 61.5 & 39.5 & 71.5 & 50.5 \\
\hline 1.9 & 58.5 & 28.5 & 63.5 & 36.0 \\
\hline 0.949 & 50.5 & 17.5 & 38.5 & 28.5 \\
\hline 0.479 & 39.5 & & & \\
\hline
\end{tabular}


In table (2) polyethylene gave 100\% mortality to Callosobruchus maculates up to 6 months but up to 5 months against Rhyzopertha dominica at $2 \mathrm{XLC}_{95}$. At tested concentration $2 \mathrm{XLC}_{95}$, polyethylene surfaces were more great persistence than cement surfaces. The concentration of $2 \mathrm{XLC}_{95}$ lambda-cyhalothrin insecticide applied on polyethylene surface still give 100\% mortality for Callosobruchus maculates up to 6 months and gradually decreased to $36.7 \%$ mortality at 12 months interval, Meanwhile, in case Rhyzopertha dominica polyethylene surface still gives $100 \%$ mortality up to 5 months and gradually decreased to $31.7 \%$ mortality at 12 months. Cement surface concentrations of lambda-cyhalothrin insecticide were deterioration very rapidly with two tested insects, it gave 100\% mortality within one month only and lost half efficiency within second months ( $58.3 \%$ and 66.3\%) with Callosobruchus maculates and Rhyzopertha dominica resp. Then, decreased gradually to $21.3 \%$ and $8.7 \%$ mortality at the sixth month with Callosobruchus maculates and Rhyzopertha dominica respectively.

Table 2: persistence of 2 XLC95 lambada-cyhalothrin insecticide on polyethylene and cement surfaces against Callosobruchus maculates and Rhyzopertha dominica adults.

\begin{tabular}{|c|c|c|c|c|c|c|c|c|c|c|c|c|c|c|c|}
\hline \multirow{2}{*}{$\begin{array}{c}\text { Initial } \\
\text { treatment }\end{array}$} & \multirow[t]{2}{*}{ Tested insects } & \multicolumn{13}{|c|}{ Months after application } & \multirow{2}{*}{ Mean } \\
\hline & & $\begin{array}{c}\text { Initial } \\
\text { treatment }\end{array}$ & 1 & 2 & 3 & 4 & 5 & 6 & 7 & 8 & 9 & 10 & 11 & 12 & \\
\hline \multirow{2}{*}{ Polyethylene } & $\begin{array}{c}\text { Callosobruchus } \\
\text { maculatus }\end{array}$ & 100 & 100 & 100 & 100 & 100 & 100 & 100 & 93.3 & 81.7 & 70.3 & 60.7 & 48.3 & 36.7 & $82.6^{a}$ \\
\hline & $\begin{array}{c}\text { Rhyzopertha } \\
\text { dominica }\end{array}$ & 100 & 100 & 100 & 100 & 100 & 100 & 98.3 & 94.3 & 87.5 & 75.3 & 63.3 & 49.3 & 31.7 & $83.3^{\mathrm{a}}$ \\
\hline Cement & $\begin{array}{c}\text { Rhyzopertha } \\
\text { dominica }\end{array}$ & 100 & 100 & 66.3 & 50.6 & 42.3 & 24.7 & 8.7 & - & - & -- & - & -- & - & $24.4^{b}$ \\
\hline Control & & 0.0 & 0.0 & 0.0 & 0.0 & 0.0 & 0.0 & 0.0 & 0.0 & 0.0 & 0.0 & 0.0 & 0.0 & 0.0 & $0.0^{c}$ \\
\hline
\end{tabular}

Means with the same letter are not significantly different

F Value 19.85

LSD 14.349

\section{DISCUSSION}

Lambada-cyhalothrin insecticide has shown differences in susceptibility between two species, but susceptibility often varies among two tested insects. Callosobruchus maculates were more susceptible than Rhyzopertha dominica to lambada-cyhalothrin. This difference in insecticide susceptibility between tested insects could be dependent on the mode of action, differences, absorption, and/or behavioral characteristics that affect exposure to that insecticide. A number of later studies showed the good potential of various contact insecticides after application on different surfaces in control of storedproduct insect pests: e.g. malathion, pirimiphos-methyl and lambda-cyhalothrin against rice wevil Sitophilus oryzae (L.) (Jankov et al., 2013). In bioassays with B. germanica (L.), Periplaneta americana (L.) and Aedes aegypti (L.) on glass, unpainted plywood, glazed ceramic tiles, unglazed tiles, cement and vinyl tiles registered high and better knockdown effects, and residual activity of lambda-cyhalothrin CS (applied at 7.5, 15 and $30 \mathrm{mg}$ $\mathrm{AI} / \mathrm{m} 2$ ) compared to WP and EC formulations Wege et al. (1999). On porous surfaces such as mud, the insecticide deposit seems to lose activity much faster than on surfaces such as wooden boards, ceramics and tiles (Penna et al., 1985).

Many studies have shown that treated surfaces with insecticide can greatly affect initial and residual activity of contact insecticides against insects ( Zettler and Arthur 
2000).On non-absorbent surfaces ( galvanized iron and polypropylene sacking), the activity of insecticides was greater.

In cement surface, lambada cyhalothrin very rapidly starting from the first month in both tested insects at cement surface, the efficacy decreased after one month with Rhyzopertha dominica and Callosobruchus maculates resp. .These results agree with Dus an Jankov et al., (2013) concluded that the lambda-cyhalothrin (CS) on concrete and plywood surfaces have the most distinctive residual efficacy against $S$. oryzae during 180 days.

\section{REFERENCES}

Abbott, W.S. (1925): A method of computing the effectiveness of an insecticide. Journal of Entomology, 18 (2): 265-267.

Anonymous (2009) Pesticides on the Serbian market. Plant Dr 2-3: 360 (in Serbian)

Collin, P.J., M. K. Nayak, R., Kopittke (2000).Residual efficacy of four organophosphate insecticides on concrete and galvanized steel surfaces against three Liposcelid Psocid species(Psocoptra:Liposcelidae) infesting stored products.Journal of Economic Entomology, 30. 1357 - 1363.

Daglish GJ (2006) Opportunities and barriers to the adoption of potential new grain protectants and fumigants. In: Lorini I,Bacaltchuk B, Beckel H, Deckers D, Sunfield E, Dos Santos JP,Biagi JD, Celaro JC, D’A Faroni LR, Bortolini L, de OF, Sartori MR, Elias MC, Guedes RNC, Da Fonseca RG, Scussel VM (eds) Proceedings of the 9th international working conference on stored product protection, 15-18 October 2006, Campinas, Brazil. ABRAPOS - Brazilian Postharvest Association, Campinas, pp 209-216.

Jankov, D., D., Indic, P., Kljajic, R., Almasi, S., Vukavic and M.,Grahovac (2013). Initial and resisual efficacy of insecticides on different surfaces against rice weevil Sitophilus oryzae (L.). Journal of Pest Sciences, 86(2): 211 - 216.

Tomlin CDS (2006). The pesticide Manual: A world compendium, 14thEd., British Crop Protection Council: Farnham, UK; pp 286-287.

Mariam A.El-Sanady and A.G.El-Sisi (2010) : Evaluation of tar oil formulated as dustable powder against grain mite Tyrophagus putrescentiae (Sharnk) (Acari:Acaridae:Acarideda). Journal of Applied Sciences, 25(4B).

Nasr, M.E.H. and S.M. Mahgoub (2017). Residual activity and persistence of deltamethrin insecticide on different surfaces against Sitophilus oryzae (L.) and Rhyzopertha dominica (F.).Egyptian Journal of Agriculture Research, 95(4),2017.

Nayak MK, Collins PJ, Kopittke RA (2002). Comparative residual toxicities of carbaryl, deltamethrin and permethrin as treatments against three liposcelidid psocid species (Psocoptera:Liposcelidae) infesting stored commodities. Journal of Stored Product Research,38:247-258

Mariam A.El-Sanady and A.G.El-Sisi (2010) . Evaluation of tar oil formulated as dustable powder against grain mite Tyrophagus putrescentiae (Sharnk) (Acari:Acaridae:Acarideda). Journal ofof Applied Sciences, 25(4B).

Penna R., Oliveira AEX, Ferreira MFN, Jonhnson C, Bosworth A , Marsdem PD (1985) .The influence of bulding materials on the residual action of BHC. Memorias instituto Oswaldo cruz, 80:443-445.

Power, C.S. and T.D. Yadav. (1980). Persistence of organophosphorus insecticides on different surfaces.Indian Journal of Entomology,42(4):728 - 736. 
Rumbos, C.I., A.C., Dutton and C.G., Arthanassiou (2014). Efficacy of two formulations pirimiphos-methyl as surface treatment against Sitophilus oryzae, Rhyzopertha dominica and Tribolium confusum.Journal of Pest Sciences, 87(3): 507 - 519.

Wege PJ, Hoppe A, Bywater AF, Weeks SD, Gallo TS (1999).A microencapsulated formulation of lambda-cyhalothrin. In:Robinson WmH, Rettich F, Rambo GW (eds) Proceedings of the 3rd international conference on urban pests, 19-22 July 1999, Prague, Czech Republic, pp 301-310.

WHO (2006). Pesticides and their application, for the control of vectors and pests of public health importance, 6th edn. World Health Organization, Geneva.

Zettler JL, Arthur FH (2000). Chemical control of stored product insects with fumigants and residual treatments. Crop Protection, 19: 577-582

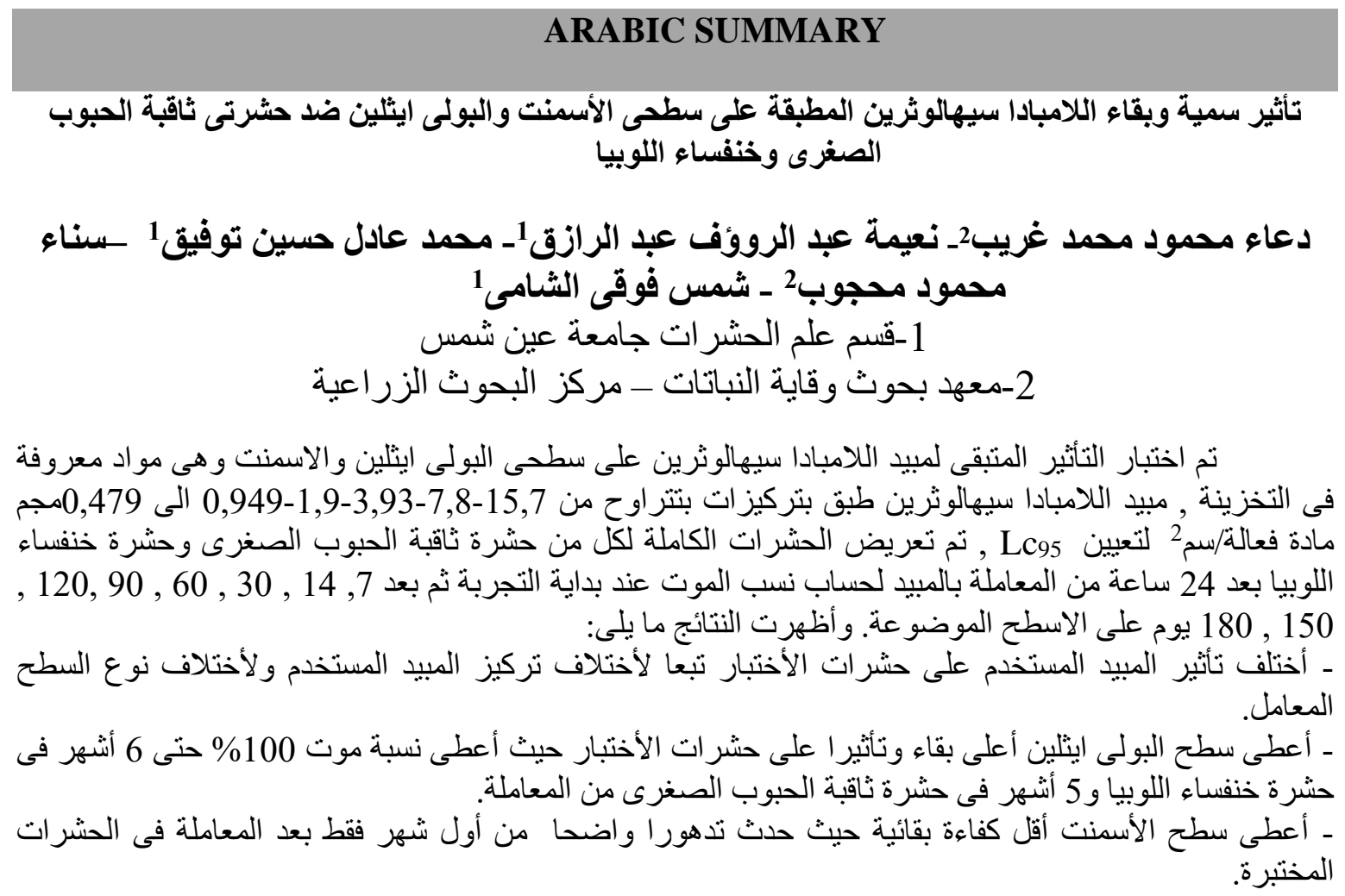

